\title{
RESTORE: A Prospective Multinational Registry of Patients with Genetically Confirmed Spinal Muscular Atrophy - Rationale and Study Design
}

Richard S. Finkel ${ }^{\mathrm{a}}$, John W. Day ${ }^{\mathrm{b}}$, Darryl C. De Vivo ${ }^{\mathrm{c}}$, Janbernd Kirschner ${ }^{\mathrm{d}}$, Eugenio Mercuri ${ }^{\mathrm{e}}$, Francesco Muntonif $^{\mathrm{f}}$, Perry B. Shieh ${ }^{\mathrm{g}}$, Eduardo Tizzano ${ }^{\mathrm{h}}$, Isabelle Desguerre ${ }^{\mathrm{i}}$, Susana Quijano-Roy ${ }^{\mathrm{j}}$, Kayoko Saito $^{\mathrm{k}}$, Marcus Droege ${ }^{\mathrm{l}}$, Omar Dabbous ${ }^{1}$, Farid Khan ${ }^{1}$, Lydie Renault ${ }^{\mathrm{m}}$, Frederick A. Anderson ${ }^{\mathrm{n}, *}$ and Laurent Servais ${ }^{\mathrm{o}}$

${ }^{a}$ Department of Pediatrics, Division of Neurology, Nemours Children's Hospital, Orlando, FL, United States

${ }^{\mathrm{b}}$ Department of Neurology, Stanford University Medical Center, Stanford, CA, United States

${ }^{\mathrm{c}}$ Departments of Neurology and Pediatrics, Columbia University Irving Medical Center, New York, NY, United States

${ }^{\mathrm{d}}$ Clinic for Neuropediatrics and Muscle Disease, University Medical Center Freiburg, Freiburg, Germany

${ }^{\mathrm{e}}$ Department of Paediatric Neurology and Nemo Clinical Centre, Catholic University, Rome, Italy

${ }^{\mathrm{f}}$ Department of Developmental Neuroscience, University College London, London, UK

${ }^{\mathrm{g}}$ Department of Neurology, David Geffen School of Medicine at UCLA, Los Angeles, CA, United States

${ }^{\mathrm{h}}$ Department of Clinical and Molecular Genetics, Hospital Valle Hebron, Barcelona, Spain

${ }^{\mathrm{i}}$ Hôpital Necker Enfants Malades, APHP, Paris

${ }^{\mathrm{j}}$ Garches Neuromuscular Reference Center (GNMH), APHP Raymond Poincare University Hospital (UVSQ), Garches, France

${ }^{\mathrm{k}}$ Institute of Medical Genetics, Tokyo Women's Medical University, Tokyo, Japan

${ }^{1}$ AveXis, Inc., Bannockburn, IL, United States

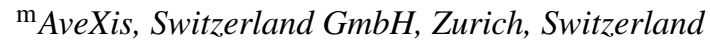

${ }^{\mathrm{n}}$ Center for Outcomes Research, University of Massachusetts Medical School, Worcester, MA, United States

${ }^{\circ}$ Oxford Neuromuscular Center, Oxford University, UK

\begin{abstract}
.
Background: Dramatic improvements in spinal muscular atrophy (SMA) treatment have changed the prognosis for patients with this disease, leading to important new questions. Gathering representative, real-world data about the long-term efficacy and safety of emerging SMA interventions is essential to document their impact on patients and caregivers.

Objectives: This registry will assess outcomes in patients with genetically confirmed SMA and provide information on the effectiveness and long-term safety of approved and emerging treatments.
\end{abstract}

\footnotetext{
${ }^{*}$ Correspondence to: Frederick Anderson, $\mathrm{PhD}$, Center for Outcomes Research (S3-310), University of Massachusetts Medical School, 55 Lake Avenue North, Worcester, MA 01655,
}

United States. Tel.: +1 508856 2275; E-mail: fred.anderson@ umassmed.edu. 
Design and Methods: RESTORE is a prospective, multicenter, multinational observational registry. Patients will be managed according to usual clinical practice. Both newly recruited SMA treatment centers and sites involved in existing SMA registries, including iSMAC, Treat-NMD, French SMA Assistance Publique- Hôpitaux de Paris (AP-HP), Cure-SMA, SMArtCARE, will be eligible to participate; de novo; sites already participating in another registry may be included via consortium agreements. Data from patients enrolled in partnering registries will be shared with the RESTORE Registry and data for newly diagnosed patients will be added upon enrollment. Patients will be enrolled over a 5-year period and followed for 15 years or until death. Assessments will include SMA history and treatment, pulmonary, nutritional, and motor milestones, healthcare resource utilization, work productivity, activity impairment, adverse events, quality of life, caregiver burden, and survival.

Status: Recruitment started in September 2018. As of January 3, 2020, 64 patients were enrolled at 25 participating sites. Conclusions: The RESTORE Registry has begun recruiting recently diagnosed patients with genetically confirmed SMA, enabling assessment of both short- and long-term patient outcomes.

Keywords: Spinal muscular atrophy, multinational, prospective, registry, outcomes, rare disease, long-term follow-up

TRIAL REGISTRATION: ClinicalTrials.gov Identifier: NCT04174157

\section{INTRODUCTION}

Spinal muscular atrophy (SMA) is a neurogenetic disorder caused by loss of or pathogenic variants in the survival motor neuron 1 gene $(S M N 1)$ on chromosome 5q13, which leads to reduced SMN protein levels and a selective dysfunction of motor neurons. SMA is an autosomal recessive spectrum of disorders, with an estimated incidence of 1:10,000 live births, 60 percent of which is the most severe form, SMA Type 1. SMA is the leading cause of infant mortality among genetic diseases [1]. SMN2 is a paralogous gene that is present in all patients and is considered a phenotype modifier. Multiple copies of SMN2 are associated with milder phenotypes [2]. Over the last 10 years, there have been numerous publications describing the natural history of patients with SMA and the effects of available supportive therapies [3-14].

Until recently, supportive medical care was the mainstay of treatment for patients with SMA. Results from recent clinical trials of gene therapy, antisense oligonucleotides, and small molecules have demonstrated that these interventions can alter the course of disease [15-20]. At the same time, standard of care guidelines have been published that support proactive intervention [15, 21, 22].

There is a need for long-term efficacy and safety information from patients receiving both existing and new therapies to document the evolving trajectory of SMA and the impact of these treatments on patient and caregiver outcomes as well as on the healthcare system. These findings promise to enhance data from long-term extensions of completed and ongoing clinical trials [23, 24]. In addition, evolving therapies raise several questions with direct impact on daily practice, such as the best prognostic factors, early identification of likely responders, reasonable expectations regarding treatment outcomes, durability of therapeutic response, and approaches to combining established and emerging therapies. Results from clinical trial extensions can be supplemented and extended by longitudinal registry data, which can play an important role in redefining the natural history of a disease resulting from the availability of disease-modifying therapies [25].

The RESTORE Registry will assess outcomes of patients with a diagnosis of 5q SMA with biallelic deletion of $S M N 1$, with the primary objective of assessing contemporary SMA treatments, including effectiveness, short- and long-term safety, and overall patient survival. RESTORE will also assess pharmacoeconomic and quality-of-care outcomes of contemporary and evolving SMA treatments, including healthcare resource utilization and caregiver burden. It was designed to overcome the recognized limitations of single-product registries [25] including difficulty in combining results for research purposes due to lack of comparability in data collected and limited access to data by academic researchers.

\section{MATERIALS AND METHODS}

\section{Design}

RESTORE is a prospective, multicenter, multinational, non-interventional observational study governed by an international steering committee of SMA experts who are committed to ensuring the quality of these data and to sharing findings through publication and presentation of Registry data. It is the first global SMA registry, consolidating data from 
Table 1

Data sources used for the RESTORE Registry

- Individual de novo clinical sites

- Existing SMA Consortia

- Managed Access Programs

- Expanded Access Programs

- Post Marketing Surveillance (required follow up)

multiple countries, established since the advent of gene therapy for SMA. All patients will be managed at participating clinical sites according to best available practices. Clinical care will not be dictated by a research protocol. No additional visits or investigations will be performed beyond those consistent with normal clinical practice. Patients will be enrolled over a 5 -year period and followed for 15 years, or until death.

Together with individual SMA treatment centers recruited de novo, participating centers may include those involved in existing and evolving SMA registries, including the International SMA Consortium (iSMAC) [24, 26], Treat-NMD [27-29], the French SMA registry, Cure SMA [30] and SMArtCARE [31]. Data from patients already enrolled in partnering registries will be transferred to the Registry database, assuming ethical approval and patient consent are obtained as required. Where inclusion of individual patient data is not feasible, aggregate data may be shared. Data for newly diagnosed patients will be added as they are enrolled by their physicians (Table 1). Motor phenotype data will be collected by trained physical therapists. Avoidance of potential duplication of counting patients among these different registries will be accomplished by assigning each patient a Global Unique Identifier. The RESTORE Registry is sponsored by AveXis (a Novartis company), manufacturer of onasemnogene abeparvovec, a gene therapy for SMA. The registry data are owned by the sponsor, which has developed bylaws providing for control of publications under the authority of a Steering Committee comprised of academic physicians and scientists with expertise in SMA.

\section{Ethical considerations}

RESTORE is being conducted in accordance with established research principles, local treatment practices and regulations, and guidelines of the International Council on Harmonisation. At centers recruited de novo, physicians will be asked to provide documentation and approvals per local regulations. Once a site is activated, physicians will consent patients using an Informed Consent Form (ICF) that has been approved by their Independent Ethics Committee/Institutional Review Board in accordance with local practices and regulations. Prior to any data collection, a written ICF and a privacy statement will be signed by the parent/guardian; and, where appropriate, by the patient. All information obtained during the conduct of the Registry with respect to the patient's identity or state of health will be treated as confidential. Prior to any disclosure of protected personal information, a signed written agreement will be obtained from the patient or his/her legal representative.

\section{Patients}

All enrolled patients must have 5q SMA diagnosed at $<18$ years of age that is genetically confirmed (biallelic loss or pathological variants of the $S M N 1$ gene) [32]. Subtypes of SMA will be categorized based on age at onset, number of SMN2 copies, and highest acquired motor function (e.g., independent sitting and ambulation). All patient recruitment and data management will be conducted in accordance with FDA/EMA requirements.

During a 5-year enrollment period, RESTORE will document the long-term safety and effectiveness of gene therapy, along with that of evolving and emerging SMA treatments, including up to 15 -years of follow-up. To minimize selection bias, consecutive eligible patients will be enrolled from participating clinical sites. To obtain adequate patient numbers to support this new observational study, an international collaboration of existing SMA registries and de novo clinical sites is being created. Patients will be recruited worldwide to provide sufficient data to document differences between patients who receive a variety of treatments.as they evolve during the 15year duration of this registry.

\section{Registry procedures}

Patient care will follow usual SMA treatment practices in each country and participating clinical site. No additional diagnostic or monitoring procedures will be required beyond the routine clinical practices at each participating clinic or hospital.

\section{Treatment}

The choice of ongoing medical treatment for the duration of the Registry will be made independently 
by the physician in the course of regular patient care and will not be influenced by participation in this Registry. Physicians are free to add or withdraw any medication but will continue to monitor each patient for the full 15 years, until death, or until the patient is withdrawn from the Registry, which may occur at the discretion of the patient or the patient's parent/legal representative or physician. No treatments will be provided by the sponsor as part of participation in this Registry.

\section{Data acquisition and variables assessed}

No mandatory visits, tests, or assessments are required for participation in this Registry. All followup visits will be scheduled and conducted according to each participating site's usual clinical practices.

\section{Data acquisition}

Sources that will generate data for this Registry include consortia, individual clinical sites, managedand expanded-access Programs (MAP/EAP), and post-marketing study obligations. Additional prospective data for SMA patients that meet RESTORE eligibility criteria may be extracted from existing registries that agree to share their information (Table 1).

Additional data will be collected from de novo study sites by local study coordinators who will complete online electronic data capture based on information in the patient's medical chart. Additionally, for de novo patients, self-reported data will be collected using standardized patient reported outcome questionnaires and caregiver surveys. Study variables (e.g., socio-demographic characteristics, history of SMA, pulmonary assessments, ventilatory support, nutritional assessment, motor milestone assessments) and standardized patient and caregiver reported outcomes assessed in the registry are listed in Table 2.

\section{Data analysis}

The analysis population will consist of all patients enrolled. The primary analysis will be a summary of outcomes stratified according to the therapy a patient is receiving at the time of enrollment. Descriptive statistics will be presented for the primary analysis. Consistent with the observational nature of this registry, no formal a priori hypothesis testing will be performed. Continuous variables will be summarized using the number of observations, mean, standard deviation, median, minimum, and maximum. Cate- gorical data will be summarized using counts and percentages. Incidence rates (per 10,000 personyears) and $95 \%$ confidence intervals for adverse events of special interest will be calculated. Survival will be evaluated using Kaplan-Meier methods. All rates and confidence intervals for individual responses will be performed on actual data. Missing observations will not be imputed in the analysis of individual questions or items.

\section{DISCUSSION}

RESTORE is a prospective, treatmentindependent, collaborative global registry. It will recruit patients from a variety of settings and backgrounds allowing assessment of short- and longterm outcomes representative of the contemporary treatment of patients with a confirmed diagnosis of SMA. To permit evaluation of patients who receive gene therapy with onasemnogene abeparvovec, this Registry will recruit patients who were previously treated in a formal clinical study or EAP/MAP.

The primary objective of the Registry is to gather long-term follow-up information on patients' outcomes that cannot be collected in the time frame of a typical clinical trial. Contemporary follow-ups from EAP programs $[31,33,34]$ or clinical trials $[15,17,18]$ do not exceed 2 years and include only patients treated with a single approach. The potential importance of inclusion of patients receiving multiple therapies is underscored by an example from the treatment of Duchenne Muscular Dystrophy, in which a registry enrolling a patient who received several therapies could permit comparison of the long-term efficacies of deflazacort and prednisone [35], and better assess the efficacy of daily treatment when compared to alternative regimens [36].

In addition, long-term data collection from a large patient sample may provide important insights regarding prognostic factors, characteristics of best responders to therapies, and estimation of the duration of unsuccessful treatment after which a patient can be considered a non-responder. Another very important question that can only be assessed by long-term follow-up is the need for and the costeffectiveness of treating pre-symptomatic patients. Even if there are few or no questions about this approach in patients with 2 or $3 S M N 2$ copies [37], this question will undoubtedly arise for patients with 4 copies, reflecting the creation of numerous newborn screening programs [38-40]. The issue of treating 
Table 2

Study variables collected in the RESTORE Registry

\begin{tabular}{|c|c|}
\hline Category & Variables \\
\hline $\begin{array}{l}\text { Confirmation of Eligibility, } \\
\text { Socio-demographics, Study Status }\end{array}$ & $\begin{array}{l}\text { - Date of informed consent for study enrollment } \\
\text { - Eligibility Assessment } \\
\text { - Socio-demographic characteristics: } \\
\text { ○ Year of Birth } \\
\text { ○ Gestational age } \\
\text { o Gender } \\
\text { ○ Race } \\
\text { o Ethnicity (US) } \\
\text { - Withdrawal of consent: } \\
\text { - Date of withdrawal } \\
\text { o Reason for withdrawal }\end{array}$ \\
\hline Clinical Characteristics of Patient & $\begin{array}{l}\text { - Medical history: } \\
\text { ○ History of SMA: } \\
\text { - Date and age of diagnosis } \\
\text { - Genetic status } \\
\text { - SMN2 copy number } \\
\text { - Point mutation } \\
\text { - Weight at diagnosis of SMA } \\
\text { - Length/height at diagnosis of SMA } \\
\text { Other medical history } \\
\text { - Family history: } \\
\text { - Maternal and paternal genetic test results }\end{array}$ \\
\hline Treatments & $\begin{array}{l}\text { - Onasemnogene abeparvovec treatment (if applicable): } \\
\text { ○ Date of treatment, dose } \\
\text { - Prednisolone treatment (onasemnogene abeparvovec group only) } \\
\text { - Nusinersen treatment: } \\
\text { o Dose and frequency } \\
\text { o Start and stop dates } \\
\text { - Other concomitant medications: } \\
\text { o Dose and frequency } \\
\text { ○ Start and stop dates }\end{array}$ \\
\hline Patient Assessments & $\begin{array}{l}\text { - Pulmonary assessments: } \\
\text { ○ Was it performed, normal/abnormal, if abnormal details } \\
\text { - Ventilatory support: } \\
\text { ○ Cough assist details } \\
\text { ○ Non-invasive details } \\
\text { ○ Invasive details } \\
\text { - Nutritional assessment: } \\
\text { o Use of non-oral procedure to administer food: } \\
\text { ○ Details including start/stop, volume, frequency, caloric intake } \\
\text { - Motor milestone assessments: } \\
\text { ○ Developmental milestones } \\
\text { ○ Children's Hospital of Philadelphia Infant Test of Neuromuscular } \\
\text { Disorders (CHOP INTEND) } \\
\text { ○ Hammersmith Infant Neurological Examination (HINE) } \\
\text { - Hammersmith Functional Motor Scale } \\
\text { - Laboratories } \\
\text { ○ Liver function test }\end{array}$ \\
\hline $\begin{array}{l}\text { Hospitalization and Healthcare } \\
\text { Resource Utilization }\end{array}$ & $\begin{array}{l}\text { - Emergency room visits and hospitalizations: } \\
\text { ○ Date of hospitalizations } \\
\text { ○ Reason of hospitalizations } \\
\text { - Other therapies and visits } \\
\text { - Insurance type (in US) }\end{array}$ \\
\hline $\begin{array}{l}\text { Patient/Caregiver Reported } \\
\text { Outcomes }\end{array}$ & $\begin{array}{l}\text { - Work Productivity and Activity Impairment Questionnaire SMAv2 } \\
\text { - Zarit Burden Interview } \\
\text { - PedsQL Child report } \\
\text { - PedsQL Parent report concerning child }\end{array}$ \\
\hline Serious Adverse Events and Death & $\begin{array}{l}\text { - Serious adverse events (and adverse events of special interest): } \\
\text { o Start and stop dates } \\
\text { - Death: } \\
\text { o Date of death } \\
\text { ○ Primary cause of death }\end{array}$ \\
\hline
\end{tabular}


presymptomatic patients has also been raised in lateonset Pompe disease [41] and this question should be addressed generally. Another important consideration related to treatment of asymptomatic patients, who are potential candidates for gene therapy, is the persistence of transgene expression, which can be determined over long-term follow-up of Registry patients.

Review of the design of existing registries suggests that the variables evaluated in RESTORE will complement and extend analyses of existing registries, including provision of important information about the clinical course of SMA in patients receiving new treatments. Ongoing discussions with the leaders of existing SMA registries indicate that there is a large overlap in the types of data collected and a willingness, consistent with the charter of each registry, to share data for the benefit of patients, families, regulatory agencies, and clinical researchers.

Given that RESTORE will provide data describing the clinical management of patients with SMA across multiple countries, there is a potential limitation due to variations in the standard of care across countries or regions, and variation in treatments based on cultural norms with the potential for missing data for some measures. This has been noted as a potential issue for all rare disease registries [25]. This is particularly important for the most severely affected patients, since they constitute the group for which the extent of medical care is the most important. In patients with less severe disease, such as those who are ambulatory, differences in standards of care are less likely to directly and significantly impact patient outcomes. Another limitation of this Registry is the absence of standard training for neuromuscular therapists, and more generally, the lack of standardization across SMA medical assessment.

RESTORE was designed to overcome the recognized limitations of single-product registries [25, 42] including difficulty in combining results for research purposes due to lack of comparability in data collected and limited access to data by academic researchers. When patients are exposed to multiple treatments, particularly at different clinics, partial data for individual patients may be stored in multiple registries. Consequently, their full experience across treatments cannot be appreciated by studying data in a single-product registry.

Comparisons of patient data may be limited due to large differences in population characteristics. Addressing this challenge in RESTORE may present an opportunity to answer critical questions about the importance of variations in patients and systems of care.

Because patients will not be randomized, statistics will be limited to comparisons of means, frequencies, and temporal trends. The prognostic factors for key milestones, including sitting for the SMA type 1 patients, or walking for type 2 and type 3 patients, will be investigated by comparing proportions of sitters and walkers according to multiple parameters, including disease duration, number of SMN2 copies, baseline conditions, etc. Our focus will be on assuring the representativeness of patients, completeness of the information collected for each patient, and the validity of study data.

Due to uncontrolled variations in scheduling follow-up care, data cannot be collected at fixed intervals. Even if all families are offered similar standards of care, some may refuse all or a portion of this support, and variations in Registry findings will reflect the heterogeneity of care delivered. In addition, some patients may choose to enroll in controlled clinical trials during the follow-up period. Loss to follow up, independent of patient status, represents another challenge for data collection and assessment.

Strengths of our design include a focus on enrolling consecutive eligible patients who were genetically diagnosed, representing a broad range of evolving SMA care practices and outcomes across many countries and health care systems. This should provide a robust characterization of the course of disease for patients with SMA receiving the full range of contemporary and evolving treatments and supportive care. Additional strengths of an observational study design include the option to modify the registry design as standards of care are advanced and experience is gained from the care of patients receiving interventions that greatly extend the lifespans of SMA patients. During the planned 15-year duration of the Registry, additional variables may be added to the data collection forms, leading to important insights into questions that were not anticipated in the original study design.

In conclusion, RESTORE is a disease registry aimed at assessing the safety and effectiveness of new and evolving treatments for SMA during a 5year enrollment period and followed for up to 15 years. This project is being undertaken with an open and collaborative approach, with the aim of combining multinational and multi-institutional resources. In addition to providing information about the longterm efficacy and safety of emerging SMA treatments that promise to revolutionize the course of disease for 
patients with SMA, RESTORE will also assess pharmacoeconomics (e.g., healthcare resource utilization, caregiver burden) and quality-of-care associated with contemporary and evolving SMA treatments. Thus, RESTORE will provide valuable insights into both the effectiveness and value of SMA therapies, representing an essential resource to inform treatment decisions and improve patient outcomes.

\section{ACKNOWLEDGMENTS/sources of support}

All financial and material support for this research was provided by AveXis, Inc., a Novartis company. As stipulated in the RESTORE bylaws, all publication topics must be authored and approved by the members of the steering committee, analyses will be performed by statisticians employed by the CRO that manages the study data. Bob Rhoades provided editorial support for this manuscript.

\section{REFERENCES}

[1] Sugarman EA, Nagan N, Zhu H, Akmaev VR, Zhou Z, Rohlfs EM, et al. Pan-ethnic carrier screening and prenatal diagnosis for spinal muscular atrophy: Clinical laboratory analysis of $>72,400$ specimens. Eur J Hum Genet. 2012;20(1):27-32. doi: 10.1038/ejhg.2011.134

[2] Calucho M, Bernal S, Alías L, March F, Venceslá A, Rodríguez-Álvarez FJ, et al. Correlation between SMA type and SMN2 copy number revisited: An analysis of 625 unrelated Spanish patients and a compilation of 2834 reported cases. Neuromuscul Disord. 2018;28(3):208-15. doi: 10.1016/j.nmd.2018.01.003

[3] Chabanon A, Seferian AM, Daron A, Péréon Y, Cances $\mathrm{C}$, Vuillerot $\mathrm{C}$, et al. Prospective and longitudinal natural history study of patients with Type 2 and 3 spinal muscular atrophy: Baseline data NatHis-SMA study. PLoS One. 2018;13(7):e0201004. doi: 10.1371/journal.pone.0201004

[4] Montes J, McDermott MP, Mirek E, Mazzone ES, Main M, Glanzman AM, et al. Ambulatory function in spinal muscular atrophy: Age-related patterns of progression. PloS One. 2018;13(6):e0199657. doi: 10.1371/journal.pone.0199657

[5] Bertini E, Mercuri E. Motor neuron disease: A prospective natural history study of type 1 spinal muscular atrophy. Nat Rev Neurol. 2018;14(4):197-8. doi: 10.1038/nrneurol.2017.189

[6] Wadman RI, Wijngaarde CA, Stam M, Bartels B, Otto LAM, Lemmink $\mathrm{HH}$, et al. Muscle strength and motor function throughout life in a cross-sectional cohort of 180 patients with spinal muscular atrophy types 1c-4. Eur J Neurol. 2018;25(3):512-8. doi: 10.1111/ene.13534

[7] De Sanctis R, Pane M, Coratti G, Palermo C, Leone D, Pera $\mathrm{MC}$, et al. Clinical phenotypes and trajectories of disease progression in type 1 spinal muscular atrophy. Neuromuscul Disord. 2018;28(1):24-8. doi: 10.1016/j.nmd.2017.09.015

[8] Kolb SJ, Coffey CS, Yankey JW, Krosschell K, Arnold WD, Rutkove SB, et al. Natural history of infantile-onset spinal muscular atrophy. Ann Neurol. 2017;82(6):883-91. doi: 10.1002/ana.25101
[9] Hashizume A, Katsuno M, Suzuki K, Hirakawa A, Hijikata Y, Yamada S, et al. Long-term treatment with leuprorelin for spinal and bulbar muscular atrophy: Natural history-controlled study. J Neurol Neurosurg Psychiatry. 2017;88(12):1026-32. doi: 10.1136/jnnp-2017-316015

[10] Qu YJ, Ge XS, Bai JL, Wang LW, Cao YY, Lu YY, et al. Association of copy numbers of survival motor neuron gene 2 and neuronal apoptosis inhibitory protein gene with the natural history in a Chinese spinal muscular atrophy cohort. J Child Neurol. 2015;30(4):429-36. doi: $10.1177 / 0883073814553271$

[11] Finkel RS, McDermott MP, Kaufmann P, Darras BT, Chung WK, Sproule DM, et al. Observational study of spinal muscular atrophy type I and implications for clinical trials. Neurology. 2014;83(9):810-7. doi: 10.1212/WNL.0000000000000741

[12] Khirani S, Colella M, Caldarelli V, Aubertin G, Boulé M, Forin V, et al. Longitudinal course of lung function and respiratory muscle strength in spinal muscular atrophy type 2 and 3. Eur J Paediatr Neurol. 2013;17(6):552-60. doi: 10.1016/j.ejpn.2013.04.004

[13] Kaufmann P, McDermott MP, Darras BT, Finkel RS, Sproule DM, Kang PB, et al. Prospective cohort study of spinal muscular atrophy types 2 and 3 . Neurology. 2012;79(18):1889-97. doi: 10.1212/WNL.0b013e31 $8271 \mathrm{f} 7 \mathrm{e} 4$

[14] Oskoui M, Levy G, Garland CJ, Gray JM, O'Hagen J, De Vivo DC, et al. The changing natural history of spinal muscular atrophy type 1. Neurology. 2007;69(20):1931-6.

[15] Mercuri E, Darras BT, Chiriboga CA, Day JW, Campbell C, Connolly AM, et al. Nusinersen versus sham control in later-onset spinal muscular atrophy. $\mathrm{N}$ Engl $\mathrm{J}$ Med. 2018;378(7):625-35. doi: 10.1056/NEJMoa1710504

[16] LoMauro A, Mastella C, Alberti K, Masson R, Aliverti A, Baranello G. Effect of nusinersen on respiratory muscle function in different subtypes of type 1 spinal muscular atrophy. Am J Respir Crit Care Med. 2019 Aug 21. doi: 10.1164/rccm.201906-1175LE

[17] Finkel RS, Mercuri E, Darras BT, Connolly AM, Kuntz NL, Kirschner J, et al. Nusinersen versus sham control in infantile-onset spinal muscular atrophy. N Engl J Med. 2017;377(18):1723-32. doi:10.1056/NEJMoa1702752

[18] Mendell JR, Al-Zaidy S, Shell R, Arnold WD, RodinoKlapac LR, Prior TW, et al. Single-dose gene-replacement therapy for spinal muscular atrophy. N Engl J Med. 2017;377(18):1713-22. doi: 10.1056/NEJMoa1706198

[19] Charnas L, Voltz E, Pfister C, Peters T, Hartmann A, Berghs-Clairmont C, et al. Safety and efficacy findings in the first-in-human trial (FIH) of the oral splice modulator branaplam in type 1 spinal muscular atrophy (SMA): interim results. Neuromuscul Disord. 2017;27(Suppl 2):S207-8. doi: https://doi.org/10.1016/j.nmd.2017.06.411

[20] Finkel RS, Chiriboga CA, Vajsar J, Day JW, Montes J, De Vivo DC, et al. Treatment of infantile-onset spinal muscular atrophy with nusinersen: A phase 2, open-label, dose-escalation study. Lancet. 2016;388(10063):3017-26. doi: 10.1016/S0140-6736(16)31408-8

[21] Wang CH, Finkel RS, Bertini ES, Schroth M, Simonds A, Wong B, et al. Consensus statement for standard of care in spinal muscular atrophy. J Child Neurol. 2007;22(8):102749.

[22] Finkel RS, Mercuri E, Meyer OH, Simonds AK, Schroth MK, Graham RJ, Kirschner J, et al. Diagnosis and management of spinal muscular atrophy: Part 2: Pulmonary and acute care; medications, supplements and immuniza- 
tions; other organ systems; and ethics. Neuromuscul Disord. 2018;28(3):197-207. doi: 10.1016/j.nmd.2017.11.004

[23] Bartlett A, Kolb SJ, Kingsley A, Swoboda KJ, Reyna SP, Sakonju A, et al. Recruitment \& retention program for the NeuroNEXT SMA Biomarker Study: Super Babies for SMA1 Contemp Clin Trials Commun. 2018;11:113-9. doi: 10.1016/j.conctc.2018.07.002

[24] ClinicalTrials.gov. Long-term follow-up study for patients from AVXS-101-CL-101 (START) (NCT03421 977). 2018 [cited 2019 Jun 15]. Available from: https:// clinicaltrials.gov/ct2/show/NCT03421977?term $=\% 22$ spin al+muscular+atrophy $\% 22 \& l u p d \_s=12 \% 2 F 06 \% 2 \mathrm{~F} 2015 \&$ lupd_d=1000.

[25] Gliklich RE, Dreyer NA, Leavy MB, editors. Registries for Evaluating Patient Outcomes: A User's Guide [Internet]. 3rd ed. Rockville (MD): Agency for Healthcare Research and Quality (US); 2014 Apr [cited 201915 Jun]. Available from http://www.ncbi.nlm.nih.gov/books/NBK208616/

[26] Mercuri E, Finkel R, Scoto M, Hall S, Eaton S, Rashid A, et al. Development of an academic disease registry for spinal muscular atrophy. Neuromuscul Disord. 2019 Aug 29.

[27] TREAT-NMD. SMA Registry Core Data. 2014 [cited 2019 15 Jun]. Available from: http://www.treat-nmd.eu/down loads/file/registries_toolkit/SMA_core_dataset_March2014. pdf

[28] Bladen CL, Thompson R, Jackson JM, Garland C, Wegel C, Ambrosini A, et al. Mapping the differences in care for 5,000 spinal muscular atrophy patients, a survey of 24 national registries in North America, Australasia and Europe. J Neurol. 2014;261(1):152-63. doi: 10.1007/s00415-013-7154-1

[29] Verhaart IEC, Robertson A, Leary R, McMacken G, König $\mathrm{K}$, Kirschner J, et al. A multi-source approach to determine SMA incidence and research ready population. J Neurol. 2017;264(7):1465-73. doi: 10.1007/s00415-017-8549-1

[30] Cure SMA. SMA Clinical Care Center Network / Clinical Data Registry \& Clinical Trials Site Readiness for SMA. 2018 [cited 2019 Jun 15]. Available from: http://www. curesma.org/documents/32118-clinical-webinar-deck.pdf.

[31] Pechmann A, König K, Bernert G, Schachtrup K, Schara U, Schorling D, et al. SMArtCARE - A platform to collect reallife outcome data of patients with spinal muscular atrophy. Orphanet J Rare Dis. 2019;14(1):18. doi: 10.1186/s13023019-0998-4

[32] Alías L, Bernal S, Fuentes-Prior P, Barceló MJ, Also E, Martínez-Hernández R, et al. Mutation update of spinal muscular atrophy in Spain: Molecular characterization of 745 unrelated patients and identification of four novel mutations in the SMN1 gene. Hum Genet. 2009;125(1):29-39. doi: 10.1007/s00439-008-0598-1
[33] Pane M, Palermo C, Messina S, Sansone VA, Bruno $C$, Catteruccia $M$, et al. Nusinersen in type 1 SMA infants, children and young adults: Preliminary results on motor function. Neuromuscul Disord. 2018;28(7):582-5. doi: 10.1016/j.nmd.2018.05.010

[34] Aragon-Gawinska K, Seferian AM, Daron A, Gargaun E, Vuillerot C, Cances C, et al. Nusinersen in patients older than 7 months with spinal muscular atrophy type 1: A cohort study. Neurology. 2018;91(14):e1312-18. doi: 10.1212/WNL.0000000000006281

[35] McDonald CM, Henricson EK, Abresch RT, Duong T, Joyce $\mathrm{NC}$, Hu F, et al. Long-term effects of glucocorticoids on function, quality of life, and survival in patients with Duchenne muscular dystrophy: A prospective cohort study. Lancet. 2018;391(10119):451-61. doi: 10.1016/S0140-6736(17)32160-8

[36] Ricotti V, Ridout DA, Pane M, Main M, Mayhew A, Mercuri E, et al. The NorthStar Ambulatory Assessment in Duchenne muscular dystrophy: Considerations for the design of clinical trials. J Neurol Neurosurg Psychiatry. 2016;87(2):149-55. doi: 10.1136/jnnp-2014-309405

[37] Glascock J, Sampson J, Haidet-Phillips A, Connolly A, Darras B, Day J, et al. Treatment algorithm for infants diagnosed with spinal muscular atrophy through newborn screening. J Neuromuscul Dis. 2018;5(2):145-58. doi: 10.3233/JND180304

[38] Boemer F, Caberg JH, Dideberg V, Dardenne D, Bours V, Hiligsmann M, et al. Newborn screening for SMA in Southern Belgium. Neuromuscul Disord. 2019;29(5):343-49. doi: 10.1016/j.nmd.2019.02.003

[39] Kraszewski JN, Kay DM, Stevens CF, Koval C, Haser B, Ortiz V, et al. Pilot study of population-based newborn screening for spinal muscular atrophy in New York state. Genet Med. 2018;20(6):608-13. doi: 10.1038/gim.2017.152

[40] Chien YH, Chiang SC, Weng WC, Lee NC, Lin CJ, Hsieh WS, et al. Presymptomatic diagnosis of spinal muscular atrophy through newborn screening. J Pediatr. 2017;190:124-9. doi: 10.1016/j.jpeds.2017.06.042

[41] Echaniz-Laguna A, Carlier RY, Laloui K, Carlier P, Salort-Campana E, Pouget J, et al. Should patients with asymptomatic Pompe disease be treated? A nationwide study in France. Muscle Nerve. 2015;51(6):884-9. doi: 10.1002/mus.24653

[42] Hollak CE, Aerts JM, Aymé S, Manuel J. Limitations of drug registries to evaluate orphan medicinal products for the treatment of lysosomal storage disorders. Orphanet J Rare Dis. 2011;6:16. doi: 10.1186/1750-1172-6-16 